\title{
Estimating Farmers' Willingness to Pay for Improved Irrigation: An Economic Study of the Bontanga Irrigation Scheme in Northern Ghana
}

\author{
Mustapha Alhassan ${ }^{1}$, John Loomis ${ }^{1}$, Marshall Frasier ${ }^{1}$, Stephen Davies ${ }^{1} \&$ Allan Andales ${ }^{2}$ \\ ${ }^{1}$ Department of Agricultural and Resource Economics, Clark B-320, Colorado State University, Fort Collins, CO, \\ USA \\ ${ }^{2}$ Department of Soil and Crop Sciences, Plant Sciences C127, Colorado State University, Fort Collins, CO, USA \\ Correspondence: Mustapha Alhassan, Department of Agricultural and Resource Economics, Clark B-320, \\ Colorado State University, Fort Collins, CO 80523, USA. Tel: 1-301-852-4134. E-mail: naanigoo@gmail.com
}

\author{
Received: December 17, 2012 Accepted: February 5, 2013 Online Published: March 15, 2013 \\ doi:10.5539/jas.v5n4p31 \\ URL: http://dx.doi.org/10.5539/jas.v5n4p31
}

\begin{abstract}
This paper estimates the willingness of farmers under the Bontanga Irrigation Scheme (BIS) in Northern Ghana to pay for improved irrigation services. The Contingent Valuation Method (CVM) was used in this study and farmers were randomly selected for interviewing based on the location of their farms (upstream, middle, and downstream) within the scheme. The payment card elicitation format was used and the data were analyzed using Maximum Likelihood Estimation (MLE) procedure that is capable of accommodating the intervals in payment card data. The mean willingness to pay was found to be GHC 16.32 (US\$ 8.50) per ha per year and the median was GHC 14.00 (US\$ 7.29) per ha per year. The study identified location of farm, land ownership, and land lease prices as the significant and influencing factors that affect willingness to pay.
\end{abstract}

Keywords: willingness to pay, bontanga irrigation scheme, contingent valuation

\section{Introduction}

Agriculture is the main source of employment and income in most developing countries, and Ghana is no exception. Agriculture accounts for the largest share of the Gross Domestic Product (GDP) of Ghana. However, its share of the GDP declined from over 44 percent in 1990 to about 37 percent in 2005, and further down to about 30.2 percent in 2010 (Ministry of Food \& Agriculture (MOFA), 2011). One would have thought that the decline in agriculture's share of the GDP is due to increases in output from other sectors (industries and services), but that is not the case. Agriculture's GDP growth rate in 2007 decreased by $1.7 \%$ and that of crops sector contribution to agriculture's share of the GDP decreased by $1.3 \%$. And from 2009 to 2010, agriculture's GDP growth rate decreased by about $26 \%$ and the crops sector contribution decreased by about $50 \%$ (Ghana Statistical Service (GSS), 2011). Several factors contribute to the gradual decline of the agricultural productivity in Ghana, and the over-dependence of the country on rain-fed agriculture may be one of them.

As revealed by the report of the Intergovernmental Panel on Climate Change (IPCC) (2007), crop yield from rain-fed agriculture in Africa is expected to decrease by $50 \%$ by the year 2020 . To mitigate this consequence of climate change, not just irrigation but improved irrigation is necessary to supplement the commonly rain-fed crop production in Africa including Ghana.

There are currently 22 government managed irrigation schemes in Ghana covering a total developed land area of about 9000 hectares (Namara, Horowitz, Nyamadi, \& Barry, 2011; MOFA, 2011). Meanwhile, Namara et al. (2011) estimated the irrigation potential of Ghana to be between 0.36 and 2.9 million hectares as of 2003. The public irrigation projects in Ghana can best be characterized by lack of maintenance and abandonment. These conditions affect irrigated crop production in Ghana, especially the northern part of the country.

The northern part of Ghana is the driest part of the country. It records lower annual rainfall and has fewer river basins as compared to the south. The Northern region is one of the largest regions in Ghana and has vast arable land which is suitable for irrigation. As part of government goals to create rural employment, reduce poverty, and ensure food security, it is prudent for the government to establish more irrigation projects and also improve the 
existing ones in the three northern regions (Northern, Upper East, and Upper West). The regions can boast of very few public irrigation schemes of which BIS is the largest.

BIS was established by the Ghana Irrigation Development Authority (GIDA) in the early 1980s. It is simply an earthen dam with water supplied by gravity to the farmlands. The reservoir of the scheme is said to be capable of storing 25 million cubic meters (about 20268 acre feet) of water, and supposed to irrigate about 495 hectares at a time (MOFA, 2011). But due to lack of improvement and regular maintenance, there is always over accumulation of silt in the conveyance and distribution systems making the system incapable of sustaining the water needs of the farmers. To increase efficiency, GiDA proposes improvement of the irrigation system: increase the developed land area, support the gravity flow with pump, fix and replace the current gates with well designed gates for proper control of turnouts at laterals, install standard weirs at every turnout for proper measuring of flows, provide more irrigation facilities including machinery (tractors, combine harvesters, dredging machines and so on), and implement regular maintenance of the irrigation project. GiDA also proposes converting the scheme into an agribusiness. In this case, the current Joint Irrigation System Management (JISM) framework under BIS would be changed into Public Private Partnership (PPP) system after the improvement. Under the PPP, the scheme will be managed by the beneficiary farmers (farmer based organizations), government, and a private farmer who is expected to utilize the newly developed land area. The private farmer will encourage participation of the other beneficiary farmers through provision of benefits to the scheme in a form of irrigation facilities, marketing of produce from the scheme, and operation and maintenance of the project. Improvement of the scheme is possible if farmers are willing to assist in recovering the costs that will result from the improvement. Thus the improvement is not necessarily about increasing the quantity of water as much as reliability and complementary capital to raise the marginal productivity of the farmer.

BIS current irrigation service charge (ISC) per hectare per year is 50 GHC (US\$ 26.04) Note $2^{2}$ which is said to be very low. So this paper will try to estimate the maximum amount (ISC per hectare per year) each farmer will be willing to pay based on the location (upstream, middle or downstream) of his/her farm, assuming the irrigation system is improved and the PPP management system is in place. The outcome will be used by the management of the BIS to determine the ISCs that will be collected annually for the improvement and also for the operation and regular maintenance of the project. The results can also provide insight to management of similar public schemes within and beyond the region in determining their ISCs assuming their schemes are improved. The methodology employed by this paper is applicable in most cases and will also be insightful to researchers in Africa who are interested in valuing non-market goods.

\section{Materials and Methods}

There are several ways we can value irrigation water and services as non-market goods. The most recognized and widely used method of valuing non-market goods such as improved irrigation is the contingent valuation method (CVM) (Cameron \& Huppert, 1989; Ready, Buzby, \& Hu, 1996). The CVM is a method used to determine individual's demand for a non-market good. It requires individuals to state their preferences for the non-market resource through their responses to WTP questions concerning the existing resource or one that is yet to be provided (Cameron \& Huppert, 1989; Bateman \& Turner, 1992; Portney, 1994; Boyle, 2003). The CVM was first introduced in 1947 in Ciriacy-Wantrup (1947) but fully implemented in Davis (1963) to estimate the value of a recreational area to hunters and wilderness lovers (Portney, 1994; Boyle, 2003), and later recommended by the NOAA Panel (1993). The CVM has its strengths and weaknesses. The elicitation format (open ended, closed ended, dichotomous choice, or payment card) used in CVM is argued to have impacts on the WTP estimates but both Loomis (1990) and Boyle et al. (1996) argued that both the open-ended and the dichotomous choice formats produce reliable results. The CVM is suitable when there is no observable data that are available for the policy option to be analyzed (World Bank, 2002). CVM is also good because it allows accounts of the socioeconomic characteristics of the respondents (Portney, 1994). BIS is not yet improved so CVM will serve as the best method to value it since CVM can be used to value resources that are yet to be provided. There are very few CVM studies on irrigation in developing countries.

Weldesilassie, Fror, Boelee, and Dabbert (2009) estimated the economic value of improved wastewater irrigation in Addis Ababa, Ethiopia. They used a CVM survey and the willingness to pay (WTP) elicitation format was double-bounded dichotomous choice with an open-ended follow-up question. The payment vehicle was annual water charge per hectare per year, which makes their study very similar to this paper. They used a standard probit, bivariate probit, and interval-data models. The mean WTP values were ETB 39.57 per hectare per year from the single-bounded model, ETB 39.10 per hectare per year from the bivariate-probit model, ETB 39.72 from the interval-data model, and ETB 35.35 from the open follow up question. Their results showed that location of farm, education, number of years with irrigation experience, and total annual yield value significantly influenced WTP. 
Based on the quality of their results, they suggested using the interval data model as the best to achieve more efficient estimates of WTP for improvement of programs. Chandrasekaran, Davarajulu, and Kuppannan (2009) estimated farmers' WTP for irrigation water in the Tamil Nadu State in India. They used CVM to study farmers' WTP for tank irrigation water under improved water supply conditions during wet and dry seasons of paddy cultivation. They randomly selected 62 respondents from the dependents of 31 tanks. The survey was face-to-face interviews made up of both closed and open-ended questions. The payment vehicle was in the form of irrigation charges per hectare per year which also makes their study comparable to this paper. They used the standard logit model to analyze the results. Their study revealed the mean value of farmers' WTP for water supplied by tank irrigation as 218.50 Indian Rupees per ha per year. They found land area and water requirement of the crops to be significant.

In Bangladesh, Akter (2007) determined the value of irrigation water in a government managed small scale irrigation project in the Homna sub-district. She used CVM to elicit farmers' WTP for the irrigation water under the government managed small scale irrigation project. The CVM scenario in her study was "government managed" since most irrigation schemes in the study area were managed by private sectors. The payment vehicle was irrigation charges per decimal land area per cropping season. Single bounded closed ended WTP with follow up protest bid questions were used in her face-to-face interviews on 300 farmers in the study area.The data from her study were analyzed using standard logit model. The mean WTP wasTaka 1670 (US\$23.85) per kani (30 decimal) land area per season. Her results revealed that age, education, family size, number of income sources, ownership of farm land had significant impacts on WTP.

In this study, a survey questionnaire was designed to follow Bateman and Turner (1992), and Boyle (2003) who proposed that a good CVM survey questionnaire should include an introductory part to help respondents understand the purpose of the survey. The non-market good should be well described and how it will be provided. The payment vehicle should be well defined (and should be what the respondent is familiar with). There should be a decision rule, the provider of the non-market good should be stated, and any other information including the method/format that will assist in the elicitation of the WTP. The survey can be face-to-face interviews, mail in, or telephone interviews. The survey for this paper was conducted using face-to-face interviews because both telephone and the mailing systems are not effective in the area.

\subsection{The Theoretical Model}

Flores (2003) explains that cost is incurred in the provision of the non-market good and to recover the cost of providing the good, we need to consider the amount of income an individual will give up after the project is implemented to keep his/her utility constant - the willingness to pay or what economists call the compensating variation. In the case of BIS, the compensating variation can be explained using the equation below:

$$
\mathrm{v}\left(\mathrm{P}^{0}, \mathrm{Q}^{0}, \mathrm{y}\right)=\mathrm{v}\left(\mathrm{P}^{1}, \mathrm{Q}^{1}, \mathrm{y}-\mathrm{C}\right)
$$

where $\mathrm{v}($.$) is the indirect utility function, \mathrm{P}^{0}$ is the current ISC, $\mathrm{P}^{1}$ is the ISC after the project is improved, $\mathrm{Q}^{\circ}$ is the current situation of the project, $\mathrm{Q}^{1}$ is the improved project, $\mathrm{y}$ is the income of the farmer, and $\mathrm{C}$ is the compensating variation which is the WTP bid of the farmer.

\subsection{The Empirical Models}

The payment card (PC) was used to elicit the WTP. The PC is suitable for this study because all the respondents were expected to have the same WTP bids from which they could select. There are also problems with the payment card including range and centering biases (Mitchell \& Carson, 1986) but Rowe, Schulze, and Breffle (1996) proposed that those problems can be minimized or totally eliminated provided an exponential payment scale is used with no truncation problem. The payment card approach is identified to conserve effort and also avoid higher non-response rate as compared to open-ended approach (Cameron \& Huppert, 1989). The difficulty with the use of payment card in the survey area is that, most of the respondents have no formal education to be able to scan through and circle their bids and will need to be prompted by the interviewer.

In the PC data analysis, the respondent's true WTP, which is denoted $\mathrm{Y}_{i}$, in (2), is assumed to be in the interval between the selected WTP, C as in (1), and the next highest WTP value on the PC (Cameron \& Huppert, 1989; Hackl \& Pruckner, 1999; Boyle, 2003). So in using the PC data to estimate average values or to estimate relationships between WTP and the variables that affect the WTP, the interval midpoints are used (Cameron \& Huppert, 1989). Cameron and Huppert (1989) also add that, valuation is non-negative and that the lognormal conditional distribution for valuations can serve as useful first approximations. 
Following Cameron and Huppert (1989), $\mathrm{Y}_{i}$ lies within lower and upper thresholds $\mathrm{B}_{\mathrm{li}}$ and $\mathrm{B}_{\mathrm{ui}}$, then $\left(\log \mathrm{Y}_{i}\right)$ lies between $\left(\log \mathrm{B}_{\mathrm{li}}\right)$ and $\left(\log \mathrm{B}_{\mathrm{ui}}\right)$. The $\mathrm{E}\left(\log \mathrm{Y}_{i} \mid \mathrm{x}_{i}\right)$ is a function of $\mathrm{g}\left(\mathrm{x}_{i}, \beta\right)$. Where $\mathrm{x}_{i}$ is the vector of the independent variables of an individual and $\beta$ is the vector of the coefficients to be estimated. To estimate $\beta$, we use the function:

$$
\left(\log Y_{i}\right)=x_{i}^{\prime} \beta+u_{i}
$$

Where $x_{i}^{\prime}$ and $\beta$ are the same as above, and $\mathrm{u}_{i}$ is the random error term assumed to be distributed normally with mean 0 and the standard deviation, $\sigma$.

Ordinary Least Squares (OLS) procedure can first be used to estimate (2) above using the logarithm of the midpoints of the WTP bids as the dependent variables. But the OLS in payment card data analysis yields biased parameter estimates, the effects of the variables on the resource value can be wrongly inferred, and it can also create biases in the overall resource value (Cameron \& Huppert, 1989). To get a more appropriate estimation procedure, we proceed with the fact that $\mathrm{Y}_{i}$ is only stated by the respondent and not observed. Its probability falls within the interval and can be expressed in the form:

$$
\operatorname{Pr}\left(\mathrm{Y}_{i} \subseteq\left(\mathrm{B}_{\mathrm{li}}, \mathrm{B}_{\mathrm{u} i}\right)=\operatorname{Pr}\left(\left(\log \mathrm{B}_{l i}-x_{i}^{\prime} \beta\right) / \sigma<z_{\mathrm{i}}<\left(\operatorname{logBui}-x_{i}^{\prime} \beta\right) / \sigma\right)\right.
$$

where $z_{i}$ is the standard normal random variable. The probability in (3) can be expressed as a difference between two standard normal cumulative density functions, $z_{\mathrm{li}}$ for the lower bound and $z_{\mathrm{u} i}$ for the upper bound in (3). Then (3) can be rewritten in the form $\varphi\left(z_{u i}\right)-\varphi\left(z_{l i}\right)$. Where $\varphi$ is the cumulative standard normal density function. Interpreting the joint probability density function for $\mathbf{n}$ independent observations as a likelihood function defined over $\beta$ and $\sigma$, the log-likelihood function is written as:

$$
\log \mathrm{L}=\sum_{i=1}^{n} \log \left[\varphi\left(Z_{u i}\right)-\varphi\left(Z_{l i}\right)\right]
$$

Equation (4) is then estimated using the maximum likelihood estimation (MLE) procedure, as the most efficient and priori superior method that can accommodate the intervals of PC data (Cameron \& Huppert, 1989). Equation (4) is therefore the model employed by this paper and the MLE is used to estimate the parameters of the PC interval data.

To compute the mean and the median WTP values, the fitted values of $\log Y_{i}$ are first constructed after the regressions. So the conditional mean of $\log Y_{i}$ is expressed in the form $x_{i}^{\prime} \beta$, and exp $\left(x_{i}^{\prime} \beta\right)$ is used to retransform $\log Y_{i}$ into $Y$, which represents the median WTP value (Cameron \& Huppert, 1989). Cameron and Huppert (1989) also suggest that, the mean of $Y$, is computed by scaling the median by exp $\left(\sigma^{2} / 2\right)$, where $\sigma$ is the standard error for each regression.

\subsection{The Study Area, Sampling Methodology, and Data Collection}

In figure 1 is the map of Northern Ghana districts and BIS is located in the Tolon/Kumbungu district. Figure 2 is the map of BIS. The study was designed to be conducted based on the locations of the farmlands within the scheme. The main point was to ensure that the data collected would be representative of the farmer population. The representative sample in this case must include farmers with different farmlands at different locations (upstream, middle, and downstream) within the scheme, which could only be obtained through stratified random sampling. Many farmers downstream had abandoned their farms, so the decision to consider farmland locations was taken because it was assumed farmers at different farmland locations may value the irrigation scheme differently. Farmland locations were initially identified by lateral numbers ( 1 to 14 ) and later converted into distances in kilometers $(\mathrm{km})$. The laterals are spaced at regular intervals which were estimated to be $0.5 \mathrm{~km}$ each. The distance from the reservoir to the first lateral was estimated to be $0.9 \mathrm{~km}$. In all, the laterals span over $6.5 \mathrm{~km}$ from lateral 1 to lateral 14 , but $7.4 \mathrm{~km}$ from the reservoir to lateral 14.

The survey was conducted on July 05, 2012 through July 09, 2012. Farmers under the 14 laterals were divided into 3 groups: the first 5 laterals were considered as upstream, laterals 6 to 10 were considered as middle, and above ten were considered as downstream. Forty (40) farmers were randomly selected from each group making up 120 farmers with the intention to interview only 100 farmers. One hundred and twenty (120) farmers were selected to make room for non-responses. The farmers took the survey very serious and some of them even mentioned that the introduction was very attractive. And within the survey period, the 100 farmers were interviewed without any non-response. 


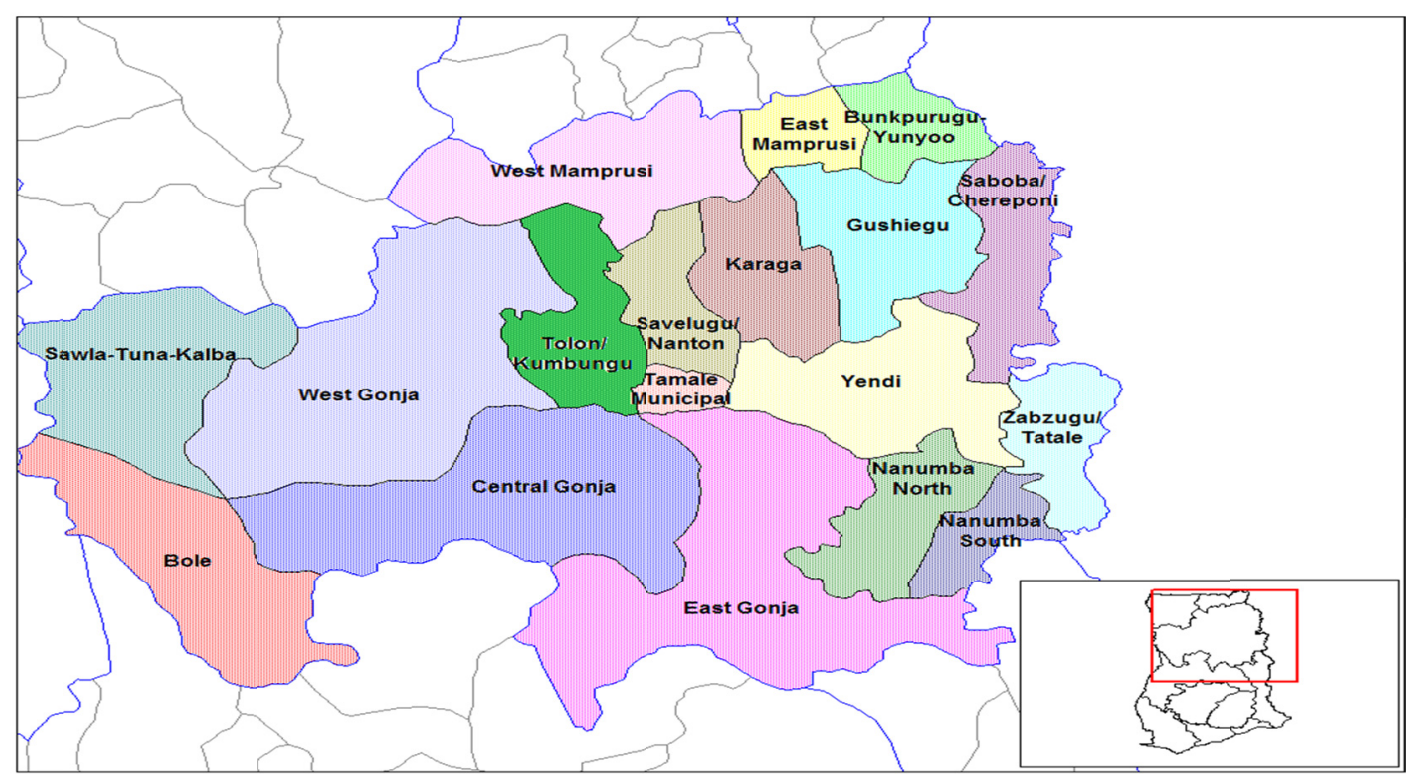

Figure 1. Map of the northern Ghana districts

Source: http://en.wikipedia.org/wiki/File: Northern_Ghana_districts.png

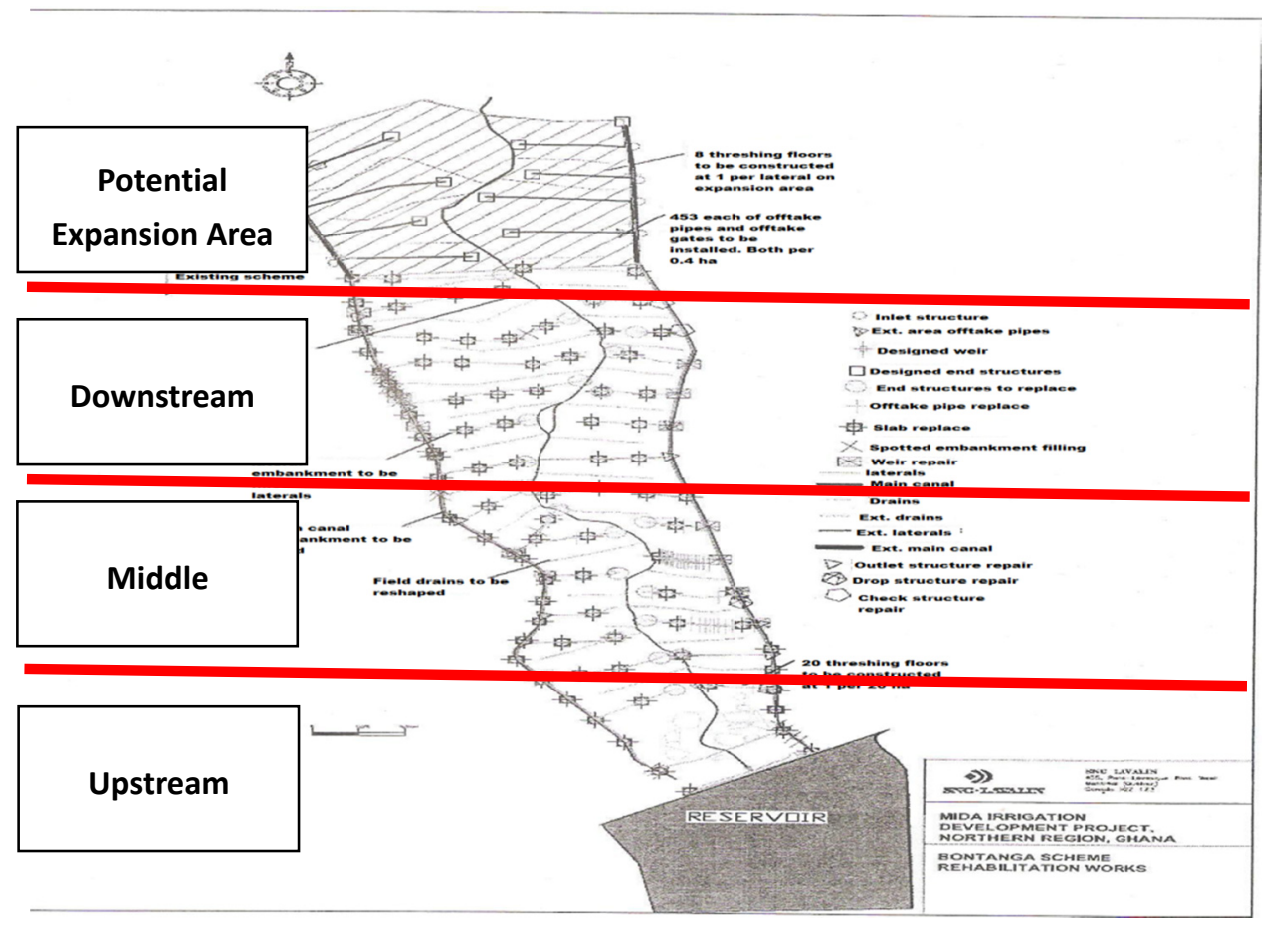

Figure 2. BIS Map

Source: MiDA Organization and Management Report, 2011.

\section{Results}

\subsection{Socioeconomic Characteristics of the Respondents}

The statistical analysis was conducted using STATA 11. Characteristics of the respondents are presented in Table 1. Out of the total of 100 respondents, $6 \%$ were females and the rest were males. Fifty nine percent $(59 \%)$ of the respondents were heads of households and the rest were in other positions including spouses of heads of 
households. The mean age of the respondents was 43.7 years. 54\% of the respondents were between 35 and 54 years. $22 \%$ were between 25 and 34 years, and $4 \%$ were below 24 years with the lowest age being 19.5 years. 15\% of the respondents were between 55 and 64 years, and $5 \%$ were above 65 years with highest age of the respondents being 69.5 years. The gender and age distributions of the respondents show that the BIS farmers are predominantly males of the active working age group (19-55 years).

The average of the highest level of education of the respondents is primary school; $73 \%$ of the respondents were without any formal education while 3\% hold second or master's degrees and above. The average household size was 16 , with 2 as the lowest household size and 65 as the highest.

Mean gross income of the respondents in 2010/2011 farm year was GHC 1760, about $67 \%$ of the respondents had their gross incomes below the mean gross income with GHC 500 as the lowest while the rest earned above the mean gross income with the highest gross income being GHC 5500. The mean scheme income of the respondents in 2010/2011 farm year was GHC 780, about $67 \%$ of the respondents earned below the mean scheme income with the lowest being GHC 150 while the rest earned above the mean scheme income with the highest as GHC 2650 . The mean off scheme income was GHC 980 , about $65 \%$ of the respondents had off scheme incomes below the mean while the rest of the respondents had off scheme incomes above the mean.

The mean farmland size of the respondents in the scheme was 0.8 ha, the least being 0.2 ha and the maximum being 2.8 ha. $6 \%$ of the respondents were said to be leasing their lands from landowners while the rest acquired their lands through families or through redistribution which they term as "balloting". This balloting occurred few years ago after most farmlands in the scheme were abandoned because most farmers resorted to farming outside the scheme. The reason for the abandonment could be due to the fact that the scheme never witnessed any major maintenance for the past 30 years of its existence. The average lease price per hectare of the farmlands based on the lease prices provided by the $6 \%$ of the respondents was GHC 24.17 .

\subsection{Willingness to Pay}

In table 2(a) is the summary of the WTP bids, their corresponding intervals, and the weighted average of the WTP midpoints. The listed values on the payment card were GHC 0, GHC 10, GHC 20, GHC 50, GHC 100, GHC 150, GHC 200, GHC 250, GHC 300, GHC 350, GHC 400, and GHC 450. The response of an individual revealed the interval within which his/her WTP could be located. If a respondent circled GHC10 for instance, his/her WTP is assumed to be between GHC 10 and GHC 20. Some respondents circled zero as their WTP bids.

There are two potential issues with responses coded in the GHC 0 and GHC 10 interval. First, the zero responses may be protest bids. A protest bid occurs when a respondent states zero value for the non-market resource but may have a value greater than zero for the resource. This behavior may be due to ethical or other reasons including rejection of some aspects of the CVM such as the scenario or the payment vehicle (Halstead, Luloff, \& Stevens, 1992; Boyle, 2003). Some respondents may state zero based on the belief that the good should be provided for free. Protest bids result in understating mean WTP or capable of biasing the aggregate benefits downward. There are no established criteria for identifying protest bids in WTP surveys because they appear problematic to identify in some cases (Boyle, 2003). Boyle (2003) also proposes that certain measures including follow up questions to obtain reasons for zero bids may be helpful, and that it is better to note that responses of individuals may suggest protests and their reasons may not. Table 2(b) is the summary of the number of the zero bids with reasons. In this case, misappropriation of the funds suggests protest response because the respondents seem to have value for the project but not sure the funds will be used as expected.

Second, the rest of the reasons in Table 2(b) may be from respondents who actually have zero value for the good. These "actual zeros", when used in the analysis as the midpoint interval of GHC 0 and GHC 10 will lead to overstatement of the mean WTP or the aggregate benefits from the improvement.

From the data, the proportion of farmers who are not willing to pay (both protest and actual zeros) is $31 \%$. The presence of both sources of error (protest and actual zeros) with countervailing impacts means that one cannot determine systematically whether estimate is an understatement or overstatement of the mean WTP. The fact is that, each error does offset the other to some extent. For this reason, the analysis was conducted with the original dataset intact. 
Table 1. Socioeconomic characteristics of respondents $(n=100)$

\begin{tabular}{llll}
\hline Characteristic & \% & Characteristic & \% \\
\hline Gender: & & Education: & \\
Female & 6 & No formal Education & 73 \\
Male & 94 & Primary School & 3 \\
Position: & & Middle/JHS & 9 \\
Head & 59 & High School & 9 \\
Other & 41 & Bachelor/Tertiary & 3 \\
Age: & & Masters and above & 3 \\
Under 24 & 4 & Gross Income (GHC/year): & \\
25-34 & 22 & $<$ GHC 1000 & 27 \\
$35-44$ & 27 & GHC 1000 and 2000 & 40 \\
$45-54$ & 27 & GHC 2000 and 3000 & 22 \\
55-64 & 15 & GHC 3000 and 4000 & 6 \\
Over 65 & 5 & $>$ GHC 5000 & 3 \\
Ownership: & & & \\
Lease & 6 & & \\
Other & 94 & & \\
\hline
\end{tabular}

Table 2(a). WTP bids, their corresponding intervals, and the weighted average of the midpoints $(n=100)$

\begin{tabular}{llll}
\hline WTP Bid (GHC) & Interval (GHC) & $\%$ & Weighted Average \\
\hline 0 & $0-10$ & 31 & 1.55 \\
10 & $10-20$ & 44 & 6.60 \\
20 & $20-50$ & 19 & 6.65 \\
50 & $50-100$ & 3 & 2.25 \\
100 & $100-150$ & 2 & 2.50 \\
150 & $150-200$ & 1 & 1.75 \\
200 & $200-250$ & 0 & 0 \\
250 & $250-300$ & 0 & 0 \\
300 & $300-350$ & 0 & 0 \\
350 & $350-400$ & 0 & 0 \\
400 & $400-450$ & 0 & 0 \\
450 & $450+$ & 0 & 0 \\
Total & & 100 & 21.30 \\
\hline
\end{tabular}

Table 2(b). Number of zero WTP Bids with reasons

\begin{tabular}{ll}
\hline Reason & Number \\
\hline Management will misappropriate the money & 19 \\
Cost of production is too high & 2 \\
Land sizes are too small & 1 \\
Crop yield is too low & 4 \\
Water is not well distributed & 2 \\
Prevalence of crop diseases & 3 \\
\hline
\end{tabular}


Table 3. Definition of the selected variables

\begin{tabular}{ll}
\hline Variable & Definition \\
\hline midptwtp & Midpoint of the WTP interval \\
lnmidptwtp & Logarithm of the midpoint of WTP interval \\
lnwtpl & Logarithm of the lower bound of the WTP interval \\
lnwtpu & Logarithm of the upper bound of WTP interval \\
locationoffarm & Location of the farmland (distance in km from the dam) \\
landin & Land size within the scheme in hectares \\
waterallocation & Dummy variable $=1$ if satisfied, 0 otherwise \\
ownership & Dummy variable $=1$ if land is leased, 0 otherwise \\
leaseprice & Lease price of the farmland in Ghana Cedis \\
sex & Dummy variable $=1$ for male, 0 for female \\
age & $19.5 \leq 24$ years, $29.5=25$ to $34,39.5=35$ to $44,49.5=45$ to 54 \\
& $59.5=55$ to $64,69.5 \geq 65$ \\
education1 & Level of education of respondent: $1=$ no formal educ., \\
& $2=$ primary school, $3=$ middle/junior high school, \\
& $4=$ high school, $5=$ first degree, \\
& $6=$ second degree and above. \\
familysize & Family size (numbers) \\
lnschemeIncome & Logarithm of the farmer's income from the scheme \\
lnoffschemeIncome & Logarithm of the farmer's income from outside the scheme \\
yield & Rice yield in kg \\
\hline
\end{tabular}

Table 4. Descriptive statistics $(n=100)$

\begin{tabular}{lllll}
\hline Variable & Mean & Std. Dev. & Min & Max \\
\hline midptwtp & 21.3 & 26.0789 & 5 & 175 \\
lnmidptwtp & 2.6437 & 0.8613 & 1.6094 & 5.1648 \\
wtpl & 13.2 & 21.2194 & 0 & 150 \\
wtpu & 29.4 & 31.2636 & 10 & 200 \\
lnwtpl $^{\text {Note 3 }}$ & 1.6467 & 1.2969 & 0 & 4.6052 \\
lnwtpu & 3.0666 & 0.7215 & 2.3026 & 5. \\
locationoffarm & 4.04 & 2.2157 & 0.9 & 7.4 \\
landin & 0.7984 & 0.5205 & 0.2 & 2.8 \\
ownership & 0.06 & 0.2387 & 0 & 1 \\
leaseprice & 1.45 & 6.5926 & 0 & 50 \\
sex & 0.94 & 0.2387 & 0 & 1 \\
age & 43.7 & 12.4056 & 19.5 & 69.5 \\
education1 & 1.75 & 1.3735 & 1 & 6 \\
familysize & 16.36 & 12.4061 & 2 & 65 \\
labordays & 5.51 & 5.3837 & 1 & 25 \\
grossIncome & 1760 & 1177.397 & 500 & 5500 \\
schemeincome & 780 & 588.6983 & 150 & 2650 \\
lnschemeincome & 6.331207 & 0.8856 & 5.0106 & 7.8823 \\
offschemeincome & 980 & 588.6983 & 350 & 2850 \\
lnoffschemeincome & 7.2433 & 0.7115 & 6.2146 & 8.6125 \\
Yield & 21.135 & 22.2897 & 0 & 125 \\
\hline
\end{tabular}


Table 5. OLS Midpoint and MLE Interval Estimates of WTP

\begin{tabular}{|c|c|c|c|c|}
\hline \multirow[t]{2}{*}{ Variable } & \multicolumn{2}{|c|}{ Main Model } & \multicolumn{2}{|c|}{ Restricted Model } \\
\hline & OLS & MLE & OLS & MLE \\
\hline \multirow{2}{*}{ Constant } & 7.0231 & $9.5363 * *$ & $2.5647 * * *$ & $2.2207 * * *$ \\
\hline & $(1.35)$ & $(2.25)$ & $(2.77)$ & $(3.02)$ \\
\hline \multirow{2}{*}{ Locationoffarm } & $-0.1172 * * *$ & $-0.0752 * *$ & $-0.1178 * * *$ & $-0.0781 * * *$ \\
\hline & $(-2.95)$ & $(-2.44)$ & $(-2.97)$ & $(-2.48)$ \\
\hline \multirow{2}{*}{ Ownership } & $1.9753 * * *$ & $1.8237 * * *$ & $1.9654 * * *$ & $1.8389 * * *$ \\
\hline & $(2.72)$ & $(2.69)$ & $(2.71)$ & $(2.75)$ \\
\hline \multirow{2}{*}{ Leaseprice } & $-0.0542 * *$ & $-0.0663 * *$ & $-0.0569 * *$ & $-0.0715^{* * *}$ \\
\hline & $(-2.07)$ & $(-2.22)$ & $(-2.19)$ & $(-2.56)$ \\
\hline \multirow{2}{*}{ Sex } & -0.0860 & -0.1558 & -0.0271 & -0.0582 \\
\hline & $(-0.21)$ & $(-0.49)$ & $(-0.07)$ & $(-0.18)$ \\
\hline \multirow{2}{*}{ Age } & 0.0073 & 0.0026 & 0.0071 & 0.0024 \\
\hline & $(0.94)$ & $(0.41)$ & $(0.91)$ & $(0.38)$ \\
\hline \multirow{2}{*}{ Education1 } & 0.0274 & 0.0515 & 0.0206 & 0.0415 \\
\hline & $(0.42)$ & $(1.04)$ & $(0.32)$ & $(0.83)$ \\
\hline \multirow{2}{*}{ Familysize } & -0.0044 & -0.0022 & -0.0074 & -0.0074 \\
\hline & $(-0.49)$ & $(-0.30)$ & $(-0.91)$ & $(-1.09)$ \\
\hline \multirow{2}{*}{ Landin } & 0.2032 & 0.2342 & 0.1903 & 0.2167 \\
\hline & $(1.00)$ & $(1.51)$ & $(0.94)$ & $(1.38)$ \\
\hline \multirow{2}{*}{ Wateralallocation } & 0.1800 & 0.1177 & 0.2068 & 0.1619 \\
\hline & $(0.89)$ & $(0.75)$ & (1.04) & $(1.02)$ \\
\hline \multirow{2}{*}{ Lnoffschemeincome } & -1.9915 & $-3.2458 *$ & & \\
\hline & $(-0.87)$ & $(-1.76)$ & & \\
\hline \multirow{2}{*}{ Lnschemeincome } & 1.5586 & $2.5995 *$ & -0.0114 & 0.0487 \\
\hline & $(0.86)$ & $(1.79)$ & $(-0.11)$ & $(0.54)$ \\
\hline \multirow{2}{*}{ Yield } & 0.0047 & 0.0037 & 0.0040 & 0.0025 \\
\hline & $(0.91)$ & $(0.93)$ & $(0.79)$ & $(0.62)$ \\
\hline \multirow{2}{*}{$\sigma$} & 0.7950 & 0.5407 & & 0.5540 \\
\hline & & $(9.8413)$ & & $(9.7784)$ \\
\hline Log likelihood & & -98.4487 & & -99.9817 \\
\hline LR chi2(12) & & $29.08 * * *$ & & $26.01 * * *$ \\
\hline Average median WTP & GHC 15.68 & GHC 14.08 & GHC 15.58 & GHC 14.00 \\
\hline Averagemean WTP per ha /year & GHC 21.51 & GHC 16.30 & GHC 21.35 & GHC 16.32 \\
\hline
\end{tabular}

Note: $* * *=$ significance at $1 \%$ level; $* *=$ significance at $5 \%$ level; $*=$ significance at $10 \%$ level. Values in parentheses are $\mathrm{t}$-values.

\section{Discussion}

All the selected variables are defined in table 3 and the descriptive statics are in Table 4. The MLE interval estimates are in Table 5. The restricted model which simply eliminates the Inoffschemeincome variable is judged to be the best after both nested likelihood ratio test and Wald test were conducted (See both Vuong, 1989; and Engle, 1984). The locationoffarm variable is significant at $1 \%$ level and proved to be negatively related to WTP. 
This makes sense because farmers who own lands downstream at BIS abandon their lands due to many problems including siltation in the BIS. One would have expected the downstream farmers to be willing to pay more for the improvement of the project, but the assumption is that they have lost hope in the project due to the long standing maintenance issues.

The ownership variable is significant at $1 \%$ level and has a positive coefficient which suggests that the willingness of landowners to pay for the improvement of the scheme is low as compared to those on lease. This makes sense because section 3.4.2 of the MiDA Organization and Management Report states that, there are land issues under the scheme and land owners who do not pay their ISCs will lose their lands in various ways, including the reallocation of the land to a family or community member (MiDA, 2011). This MiDA report reveals lack of well defined property rights with regard to land under the scheme. This might be the cause of land owners' unwillingness to invest in the project. Leaseprice variable is significant at $1 \%$ level and has a negative sign on its coefficient. This conforms to economic theory.

\section{Conclusions}

The main aim of this paper was to determine how much farmers under the Bontanga Irrigation Scheme would be willing to pay for the improvement of the project. From the results, the median WTP was calculated as GHC14.00 (US\$ 7.29) per ha per year and the mean WTP was calculated as GHC 16.32 (US\$ 8.50) per ha per year. The median WTP value represents the amount $50 \%$ of the farmers will be willing to pay and at the same time it represents the amount $50 \%$ of the farmers will not be willing to pay. The mean represents the average amount an individual farmer will be willing to pay for the improvement of the project. The significant and most influencing factors that were identified to affect WTP of farmers are location of the farm, ownership, and land lease prices. Farmers upstream had higher willingness to pay for the improvement as compared to farmers downstream and in the middle. WTP decreases as the distance from the reservoir increases. Land owners have lower willingness to pay for the improvement as compared to lessees. This appears contrary to what one would expect but there appear to be land ownership issues under the scheme which are clearly stated under section 3.4.2 in the MiDA Organization and Management Report (2011). The MiDA report states that, land owners who do not pay their ISCs may lose their lands to either family or community members.

This study provides a useful insight to the limited research in WTP for irrigation improvement in Ghana. So based on the results from this study, BIS could consider benefit cost analysis of the project to see if the total benefits from the improvement of the project would outweigh the total costs before charging farmers the new ISC. The aggregate benefits per year for the improvement of BIS assuming each farmer is expected to pay the mean WTP amount can be calculated as GHC 9302.40 (US\$ 4845.00) which is obtained by multiplying the mean WTP (GHC 16.32 per ha per year (US\$ 8.50)) by the current irrigated land area ( $570 \mathrm{ha})$. This aggregate benefits value does not reflect the additional benefits to the scheme when the irrigated land is expanded.

\subsection{Limitations to the Study}

Obtaining accurate measures of the respondents' farm outputs appeared to be difficult because farm outputs were often expressed in nonstandard units such as bags (rice especially), and had to be converted into kilograms. But those which were expressed in baskets (vegetables in particular) could not be converted into standard units. This conversion could be imprecise because a bag of "rough rice" under the scheme was estimated as $1 \mathrm{~kg}$. Also, because majority of the farmers in the scheme lack formal education, they rarely keep individual farm records which made it difficult for us to retrieve their farm data.

Another factor that might affect WTP of farmers in the catchment area is their political inclinations. It would not be surprising for farmers in developing countries to understate or overstate their WTP bids based on their political party affiliations. One next study on the scheme should try to implicitly or explicitly elicit information about the political party affiliations of the farmers to find out the differences in WTP bids that might result from their political values.

Lastly, land ownership under the scheme seems not to be well defined because some farmers were not willing to disclose their total land sizes because of the fear of redistribution, which they said occurred some years ago. In this case, it is hard to get accurate farm data which are related to land sizes of the farmers.

\subsection{Opportunities for Further Studies}

1. The next step recommended is to conduct cost benefit analysis of the scheme to see if increasing the irrigation service charges based on this study would be beneficial. 
2. Since location appears to be very important (significant) in all the WTP regressions, the next study under the scheme could try to control for location by estimating WTP for different locations (upstream, middle, and downstream) to see if WTP values for the locations will differ considerably.

3. If funding is available, researchers might consider estimating WTP for the two different seasons (wet and dry). This is because the level of utilization of the project depends on the season and this might create variations in WTP across seasons

4. Since income (both scheme and off scheme) appear not to be significant in the best model, another study may try to estimate the amount of labor days the farmers will be willing to contribute towards the improvement and regular maintenance of the project as an alternative to monetary payment.

\section{References}

Akter, S. (2007). Farmers' Willingness to Pay for Irrigation Water Under Government Managed Small Scale Irrigation Projects in Bangladesh. Journal of Bangladesh Studies, 9, 21-31.

Bateman, I. J., \& Turner, R. K. (1992). Evaluation of the Environment: The Contingent Valuation Method. CSERGE Working Paper GEC 92-18. Retrieved from http://cserge.ac.uk/sites/default/files/gec_1992_18.pdf

Bolyle, K. J. (2003). Contingent Valuation in Practice. In P. A. Champ, K. J. Boyle, \& T. C. Brown (Eds.), A Primer on Nonmarket Valuation (pp. 111-158). Dordrecht, Netherlands: Kluwer Academic Publishers. http://dx.doi.org/10.1007/978-94-007-0826-6_5

Boyle, K. J., Johnson, F. R., McCollum, D. W., Desvousges, W. H., Dunford, R. W., \& Hudson, S. P. (1996). Valuing Public Goods: Discrete Versus Continuous Contingent-Valuation Responses. Land Economics, 72, 381-396. http://dx.doi.org/10.2307/3147204

Cameron, T. A., \& Huppert, D. D. (1989). OLS versus ML Estimation of Non-market Resource values with Payment Card Interval Data.Journal of Environmental Economics and Management, 17, 230-246. http://dx.doi.org/10.1016/0095-0696(89)90018-1

Chandrasekaran, K., Devarajulu, S., \& Kuppannan, P. (2009). Farmers' Willingness to Pay for Irrigation Water: A Case of Tank Irrigation Systems in South India. Water, 1(1), 5-18. http://dx.doi.org/10.3390/w1010005

Ciriacy-Wantrup, S. V. (1947). Capital returns from soil-conservation practices. Journal Farm Economics, 29, 1181-1196. http://dx.doi.org/10.2307/1232747

Davis, R. K. (1963). Recreation Planning as an Economic Problem. Natural Resources Journal, 3, 239-49.

Engle, R. F. (1984). Wald, Likehood Ratio, and Lagrange Multiplier Tests in Econometrics. In Z. Griliches, \& M. D. Intriligator (Eds.), Handbook of Econometrics, Volume II, 776-826. Amsterdam: Elsevier Science Publishers BV.

Flores, N. E. (2003). Conceptual Framework for Nonmarket Valuation. In P. A. Champ, K. J. Boyle, \& T. C. Brown (Eds.), A Primer on Nonmarket Valuation, 27-58. Dordrecht, The Netherlands: Kluwer Academic Publishers. http://dx.doi.org/10.1007/978-94-007-0826-6_2

Hackle, F., \& Pruckner, G. J. (1999). On the gap between Payment Card and Closed-ended CVM answers. Applied Economics, 31, 733-742. http://dx.doi.org/10.1080/000368499323940

Halstead, J. M., Luloff, A. E., \& Stevens, T. H. (1992). Protest Bidders in Contingent Valuation. Northeastern Journal of Agricultural and Resource Economics, 21, 160-169.

Intergovernmental Panel on Climate Change (IPCC). (2007). Fourth Assessment Report: Climate Change. Geneva. Retrieved from http://www.ipcc.ch/publications_and_data/ar4/syr/en/spms3.html

Loomis, J. (1990). Comparative Reliability of the Dichotomous Choice and Open-Ended Contingent Valuation $\begin{array}{llllll}\text { Techniques.Journal of Economics and } & \text { Management, } & 18, & \text { 78-85. }\end{array}$ http://dx.doi.org/10.1016/0095-0696(90)90053-2

Mitchell, R. C., \& Carson, R. T. (1986). The Use of Contingent Valuation Data for Benefit-Cost Analysis in Water Pollution Control. Final Report to the Environmental Protection Agency, Resources for the Future, Washington, DC.

Namara, E. R., Horowitz, L., Nyamadi, B., \& Barry, B. (2011). Irrigation Development in Ghana: Past Experiences, Emerging Opportunities, and Future Directions. GSSP Working Paper \#27, International Food Policy Research Institute, Washington D.C.

NOAA Panel. (1993). Report of the NOAA Panel on Contingent Valuation. Washington D.C. 
Portney, P. R. (1994). The Contingent Valuation Debate: Why Economists Should Care. Journal of Economic Perspective, 8(4), 3-17. http://dx.doi.org/10.1257/jep.8.4.3

Ready, R. C., Buzby, J. C., \& Hu, D. (1996). Differences between Continuous and Discrete Contingent Value Estimate. Land Economics, 72, 397-411. http://dx.doi.org/10.2307/3147205

Republic of Ghana Ministry of Food and Agriculture. (2011). Retrieved from http://mofa.gov.gh

Republic of Ghana Statistical Service. (2011). Revised Gross Domestic Product 2010.

Republic of Ghana, Millennium Development Authority. (2011). Organization and Management Report.Bontanga andGolinga Irrigation Schemes - Lot 1. Revised by GIDA.

Rowe, R. D., Schulze, W. D., \& Breffle, W. S. (1996). A Test for Payment Card Biases.Journal of Environmental Economics and Management, 31, 178-185. http://dx.doi.org/10.1006/jeem.1996.0039

Vuong, Q. H. (1989). Likelihood Ratio Test for Model Selection and Non-nested Hypothesis. Econometrica, 57, 307-333. http://dx.doi.org/10.2307/1912557

Weldesilassie, A. B., Fror, O., Boelee, E., \& Dabbert, S. (2009). The Economic Value of Improved Wastewater Irrigastion: A Contingent Valuation Study in Addiss Ababa, Ethiopia. Journal of Agricultural and Resource Economics, 34, 428-449.

World Bank. (2002). Contingent Valuation, Environmental Economics and Development Policy Course. Washington D.C. 15-26 July. Retrieved 9 December, 2012, from http://en.wikipedia.org/wiki/File:Northern_Ghana_districts.png

Notes

Note 1: From a thesis submitted to the Academic Faculty of Colorado State University in partial fulfillment of the requirements for the degree of Master of Science;

Note 2: US\$ 1 traded for about GHC 1.92 as of August 25, 2012;

Note 3: $\mathrm{Wtpl}=0$ is not transformed but used as lnwtpl $=0$ in the MLE interval analysis. 